Investigations

\title{
WLHP Systems in Commercial Buildings: A Case Study Analysis Based on a Dynamic Simulation Approach
}

\author{
Giovanni Barone, Annamaria Buonomano, Cesare Forzano and Adolfo Palombo \\ DII, Department of Industrial Engineering, University of Naples Federico II, P.le Tecchio, 80, 80125 Naples, Italy
}

\author{
Article history \\ Received: 03-08-2016 \\ Revised: 30-08-2016 \\ Accepted: 31-08-2016 \\ Corresponding Author: \\ Annamaria Buonomano \\ DII, Department of Industrial \\ Engineering, University of \\ Naples Federico II, P.le \\ Tecchio, 80, 80125 Naples, Italy \\ Email: \\ annamaria.buonomano@unina.it
}

\begin{abstract}
In this study, the results of the performance analysis of a WLHP system applied to a large mall building located close to Naples (South Italy) is presented. The investigation was carried out through a purposely developed dynamic simulation model conceived for building-WLHP systems analyses. Through such computer tool, hourly, daily and seasonal system energy, economic and environmental assessments can obtained. For the developed case study the results of the WLHP system optimization procedure are also reported. A comparison of the modeled WLHP system Vs. traditional HVAC ones is also performed. Encouraging energy, economic and environmental results are achieved.
\end{abstract}

Keywords: WLHP System, Building-HVAC System Simulation, Energy Efficiency

\section{Introduction}

The adoption of Water Loop Heat Pump (WLHP) systems can be successfully considered in buildings with simultaneous demands of heating and cooling energy (ASHRAE, 2005; Wang, 2001). Basically, a WLHP system consists of a set of reverse cycle heat pump units interconnected by a water loop which acts as a thermal energy source/sink. Through such water loop, the chiller condenser water heat from units in cooling mode is recovered and used as a heat source for units in heating mode. This allows the heat in excess from cooling load spaces to be recovered and transferred to spaces to be heated. In the water loop eventual heating or cooling deficits are counterbalanced by additional heaters or cooling towers.

Typical WLHP systems applications are edifices with distinguished core and perimeter zones or commercial building with deep freeze or cold stores. Here, during winter and in the middle seasons heating and cooling are simultaneously required. A basic scheme of a watersource heat pump system is reported in Fig. 1.

A remarkable interest of researchers and contractors regarding the energy and economic performance of such systems has been recently observed. Recently, few studies were carried out aiming at analyzing the system component features and the relative operating parameters in relation to weather conditions (Gottfried et al., 1997; Lian et al., 2005; Xinguo, 1998; Pérez-Lombard et al., 2011). In particular, an analysis of the energy saving potential of WHLP system applications in China is presented in (Lian et al., 2005), whereas an investigation of the building typologies in which the system can be adopted is carried out, by taking into account different control strategies, in (Chen et al., 2005).

The analysis of the effect of the water temperature on the compressor and cooling tower performances is carried out in (Yuan and Grabon, 2011); such analysis is aimed at providing a practical strategy to determine the optimal WLHP system temperature. A comprehensive study on the operating conditions of the WLHP system in different European climates was developed by the authors of this paper in (Buonomano et al., 2012). In particular, the WLHP system performances and energy saving rates (also compared to traditional airconditioning systems), are analyzed through a purposely designed dynamic simulation model. Such model, implemented in MatLab, allows assessing the hourly, daily and seasonal WLHP system performances from energy, economic and environmental points of views, starting from building materials features, design and operating WLHP system parameters, as well as hourly climatic zone weather files. The simulation tool also includes the possibility to carry out suitable parametric analyses, which can be easily performed through a single simulation run. This feature provides greater support for the optimization of the system operation in order to reduce its energy consumption. For comparison purposes, additional models related to several conventional systems were also implemented in the code (Buonomano et al., 2012). 


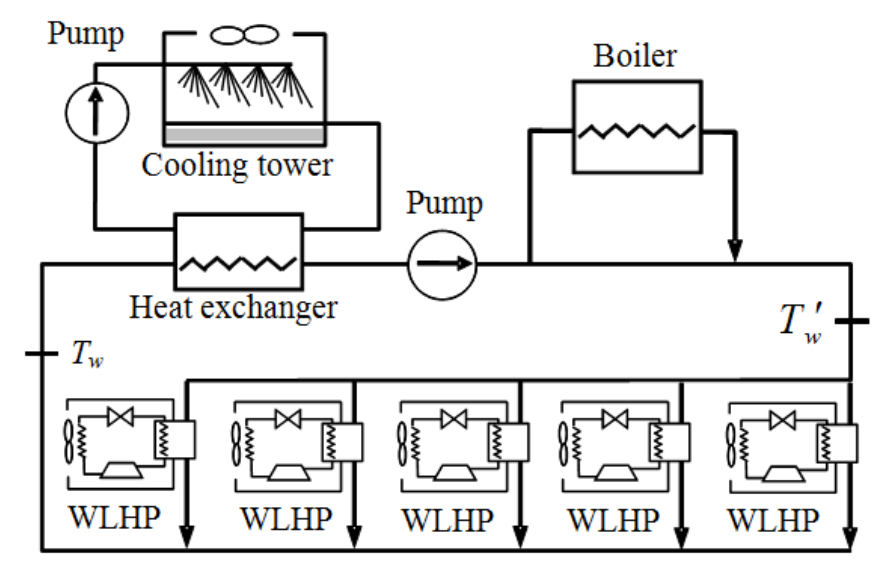

Fig. 1. Basic scheme of a WLHP system

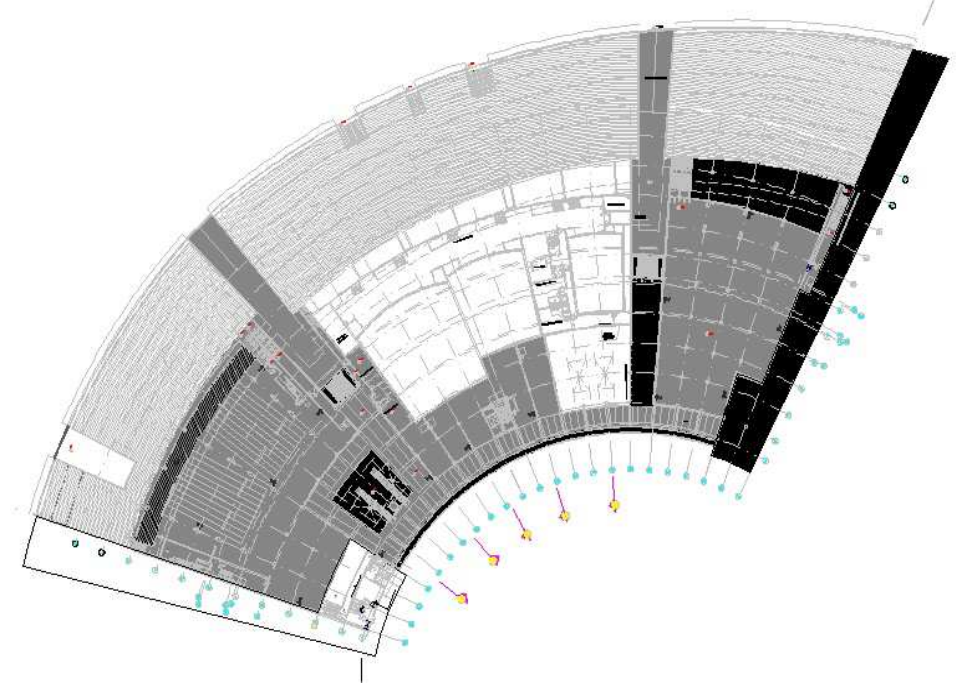

Fig. 2. C-shaped pavilion of "Vulcano Buono"

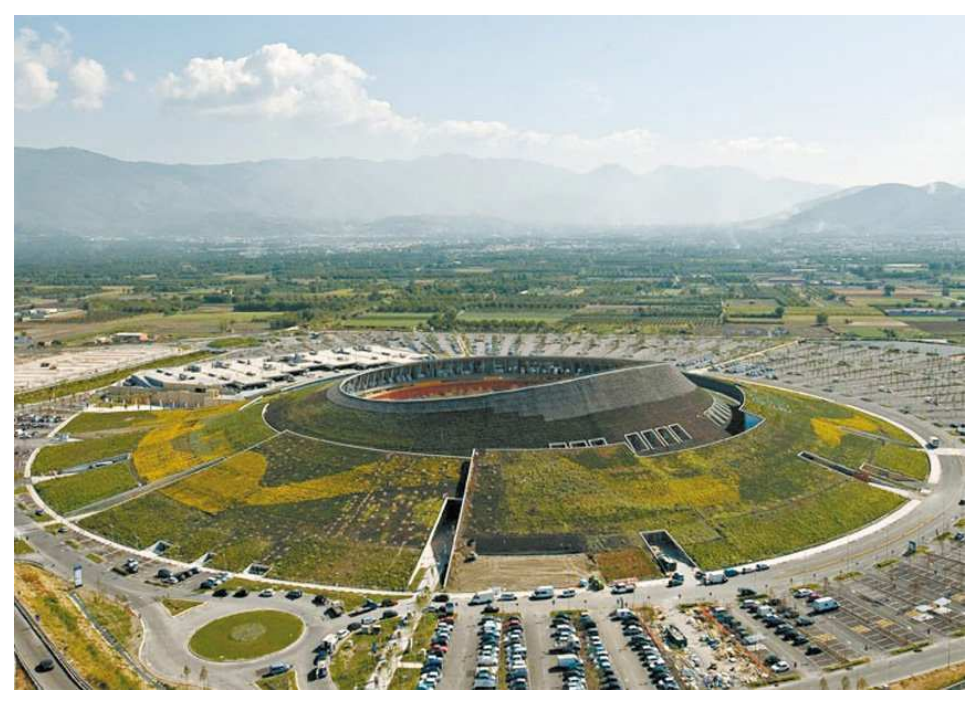

Fig. 3. "Vulcano Buono" (close to Naples-South Italy) 
In this study, through such code, an energy performance analysis of the WLHP system referred to a large commercial building pavilion (Fig. 2, including about 5 very large stores, 20 restaurants or fast foods, 10 cinemas and a large gallery) is presented.

The investigated mall is a C-shaped part of the large commercial center called "Vulcano Buono" (located close to Naples-South Italy, Mediterranean weather zone), Fig. 3. The whole cone structure, designed by Renzo Piano, includes multiple levels and a sloping roof fully covered by vegetation. Among the possible alternative HVAC plants, a wide WHLP system was preferred in order to efficiently provide heating and cooling to all the indoor spaces without affecting the architectural building design.

A suitable parametric analysis was also carried out in order to identify the optimal set of design and operating parameters optimizing the system efficiency. Several details about the system economics are also provided.

\section{Modelling and Simulation}

For both WLHP system and Traditional HVAC (THVAC) one, a performance analysis model has been developed. By its computer implementation, a sensitivity analysis varying the systems operating parameters has been also carried out with the aim to maximize the energy savings without affecting the indoor comfort.

Building-plant simulations have been carried out by means of a previously developed simulation tool, whose features are described in (Buonomano et al., 2012).

\section{WLHP System Model}

The loop water temperature $T_{w}^{\prime}$, entering to the WLHPs (Fig. 1) is modeled by taking into account the relative typical running constraints of such devices, Table 1 (CLIVET, 2007).

In order to balance the eventual water loop thermal energy deficits a natural gas boiler is considered. Here the heat provided in the $h$-th hour is:

$$
Q_{B}(h)=\dot{Q}_{B} \cdot \theta_{B}(h)=\left[\dot{m}_{w}(h) \cdot c\left(T_{w}^{\prime}(h)-T_{w}(h)\right)\right] \cdot h
$$

where, $\dot{Q}_{B}$ is the design boiler capacity, $\theta_{B}(h)$ is the boiler running hourly ratio, $\dot{m}_{w}(h) \cdot c$ is the product of the water loop mass flow rate in the $h$-th hour by the liquid water specific heat while $T_{w}(h)$ and $T_{w}^{\prime}(h)$ are respectively the entering and exiting water temperature of the boiler in the $h$-th hour. The latter is modeled as a function of spaces loads, WLHPs operating mode and weather data.

Table 1. WLHPs temperature limits

\begin{tabular}{ll}
\hline $10 \leq T_{w}^{\prime} \leq 23^{\circ} \mathrm{C}$ & heating mode \\
$15 \leq T_{w}^{\prime} \leq 45^{\circ} \mathrm{C}$ & cooling mode \\
\hline
\end{tabular}

The hourly operating boiler primary energy consumption and economic cost result respectively:

$$
\begin{aligned}
& E_{B}(h)=\frac{Q_{B}(h)}{\eta_{B}} \\
& C_{g, B}(h)=\frac{Q_{B}(h)}{\eta_{B} \cdot L H V} c_{g}
\end{aligned}
$$

being, $\eta_{B}$ the boiler efficiency, $L H V$ the natural gas lower heating value and $c_{g}$ the natural gas unitary cost (Ferruzzi et al., 2016).

In order to eventually decrease the temperature of the WLHPs supply water, a cooling tower is considered. Here, the hourly water exiting temperature is calculated by:

$$
T_{w}^{\prime}(h)=T_{w}(h)-\eta_{C T}\left(T_{w}(h)-T_{w b}(h)\right)
$$

where, $\eta_{C T}$ is the cooling tower efficiency and $T_{w b}(h)$ is the wet bulb outdoor temperature varying according to the profile of the Test Reference Year (TRY) weather data. Therefore, $T_{w}^{\prime}(h)$ depends on the outdoor climate while the cooling tower running logic is function of spaces loads and WLHPs operating mode.

The TRY is a collection of weather data files in which, for several European climatic regions, outdoor hourly dry bulb temperature, relative humidity and solar radiation are available (CEC, 1985). By such data and taking into account the thermal features of the building materials, in relation to the $h$-th hour of the considered observation period, the cooling $\dot{Q}_{\text {Cool }}(h)$ and heating $\dot{Q}_{\text {Heat }}(h)$ operating loads external to the building are calculated. The ventilation load is also included by taking into account the minimum required outdoor airflow rates referred to the specific spaces uses. For the hourly internal operating loads, people, artificial lights and electric devices are considered. The first one is assessed by the typical crowding indexes in relation to the indoor spaces uses. For the lights and electric devices contribute, suitable ratings are given as a function of the spaces utilization.

The primary energy consumption and operating economic cost of the cooling tower in each $h$-th hour are respectively:

$$
\begin{gathered}
E_{C T}(h)=\frac{\dot{L}_{C T} \cdot h}{\eta_{e} \cdot \eta_{P}} \\
C_{e, C T}(h)=\frac{\dot{L}_{C T} \cdot h}{\eta_{e}} c_{e}
\end{gathered}
$$

being, $\dot{L}_{C T}$ the electricity rating of cooling tower fans and pumps, $\eta_{e}$ the efficiency of the relative electric 
motors, $\eta_{p}$ the conventional average electricity production efficiency at power plant and $c_{e}$ the electricity unitary cost. The cooling tower water consumption is here disregarded.

The loop water at $T_{w}^{\prime}$ reaches each WLHP where the following calculation procedure is carried out. Starting from the space design cooling load of each building space, a specific WLHP is selected at the design water loop inlet temperature, Table 2. By decreasing supply water loop temperatures, variable cooling capacities $\dot{Q}_{E v}(h)$ and compressor ratings $\dot{L}_{C}(h)$ are accounted all over the simulated cooling period (Chen et al., 2005). When an outgoing space heat load is detected the WLHP heating configuration is activated. Also in this case, by varying the supply loop water temperatures new heating capacities $\dot{Q}_{C o}(h)$ and compressor ratings $\dot{L}_{C}(h)$ are considered (Chen et al., 2005).

Subsequently, the following hourly heat fluxes are respectively assessed for each indoor space.

Cooling:

$$
Q_{E v}(h)=\dot{Q}_{E v}(h) \cdot \theta_{C}(h)=\dot{Q}_{C o o l}(h) \cdot h
$$

\section{Heating:}

$$
Q_{C o}(h)=\dot{Q}_{C o}(h) \cdot \theta_{C}(h)=\dot{Q}_{H e a t}(h) \cdot h
$$

where, $\theta_{C}(h)$ is the hourly rate in which each WLHP compressor is switched on.

The following primary energy consumption and electricity cost are expected for all the WLHPs in the $h$ th hour respectively:

$$
\begin{gathered}
E_{W L H P}=\left[\sum_{i=1}^{n}\left(\dot{L}_{C}(h) \cdot \theta_{C}(h)\right)_{i}\right] / \eta_{P} \\
C_{e, \text { WLHP }}=\left[\sum_{i=1}^{n}\left(\dot{L}_{C}(h) \cdot \theta_{C}(h)\right)_{i}\right] c_{e}
\end{gathered}
$$

being, $i$ the single building space where a WLHP is installed. This energy consumption is added to the eventual one due to the boiler or to the cooling tower running in the same simulation hour:

$$
C_{e, T O T}(h)=C_{g, B}(h)+C_{e, C T}(h)+C_{e, W L H P}(h)
$$

Obviously, in the single hour only one between $C_{g, B}(h)$ and $C_{e, C T}(h)$ can be unequal to zero. In the occurring $h$ hour the $T_{w}$ to be considered in the next simulation time step $(h+1)$ is calculated by the following energy balance:

$$
\begin{gathered}
\sum_{i=1}^{n}\left(\dot{Q}_{C b}(h) \cdot \theta_{C}(h)\right)_{i, \text { Cool }}-\sum_{i=1}^{n}\left(\dot{Q}_{E v}(h) \cdot \theta_{C}(h)\right)_{i, \text { Heat }}= \\
=\left[\dot{m}_{w}(h) \cdot c\left(T_{w}(h)-T_{w}^{\prime}(h)\right)\right]
\end{gathered}
$$

If on the water loop the global heat rejected by the WLHPs running in cooling mode is higher than the global cooling load of the heating WLHPs, than: $T_{w}>T_{w}^{\prime}$ and vice versa. In Fig. 4 the WLHP temperature control flow chart is reported.

At the end of the simulation loop the WLHP system total operating cost is computed by:

$$
C_{e, \text { year }}=\sum_{h}^{\text {year }}\left(C_{g, B}(h)+C_{e, C T}(h)+C_{e, W L H P}(h)\right)
$$

In Table 2 the assumptions considered for the WLHP system simulation are summarized. The considered boiler and cooling tower running logics are shown in the following.

\section{THVAC System Model}

Each building space air handling unit is supplied by chilled or hot water as a function of the occurring cooling or heating space loads. In the present simulation it is assumed that such processes are obtained alternatively by the following systems:

- Air to Water $(A W)$ chiller and gas fired boiler for cooling and heating running, respectively

- Water to Water $(W W)$ chiller (supported by Cooling Tower, CT) and gas fired boiler for cooling and heating running, respectively

Such devices are sized on the same building design cooling and heating loads (previously calculated). In relation to the $A W$ chiller system the following algorithm is implemented in the code to assess the heat extracted from the whole building on each simulation hour, $h$ :

$\dot{Q}_{E v}^{A W}(h) \cdot \theta_{E v}^{A W}(h)=\dot{Q}_{C o o l}(h) \cdot h$

where, $\dot{Q}_{E v}^{A W}(h), \dot{L}_{C}^{A W}(h)$ and $\theta_{E v}^{A W}(h)$ are respectively the evaporator capacity, the compressor rating and the running hourly ratio in the $h$ hour of the $A W$ chiller traditional system. Note that $\dot{Q}_{E v}^{A W}(h)$ and $\dot{L}_{C}^{A W}(h)$ in the simulation code depend hour by hour on the outdoor dry bulb temperature following the TRY profile.

The $A W$ chiller system hourly primary energy consumption and operating cost result, respectively:

$$
\begin{aligned}
& E_{A W}(h)=\dot{L}_{C}^{A W}(h) \cdot \theta_{E v}^{A W}(h) / \eta_{P} \\
& C_{e, A W}(h)=\dot{L}_{C}^{A W}(h) \cdot \theta_{E v}^{A W}(h) \cdot c_{e}
\end{aligned}
$$




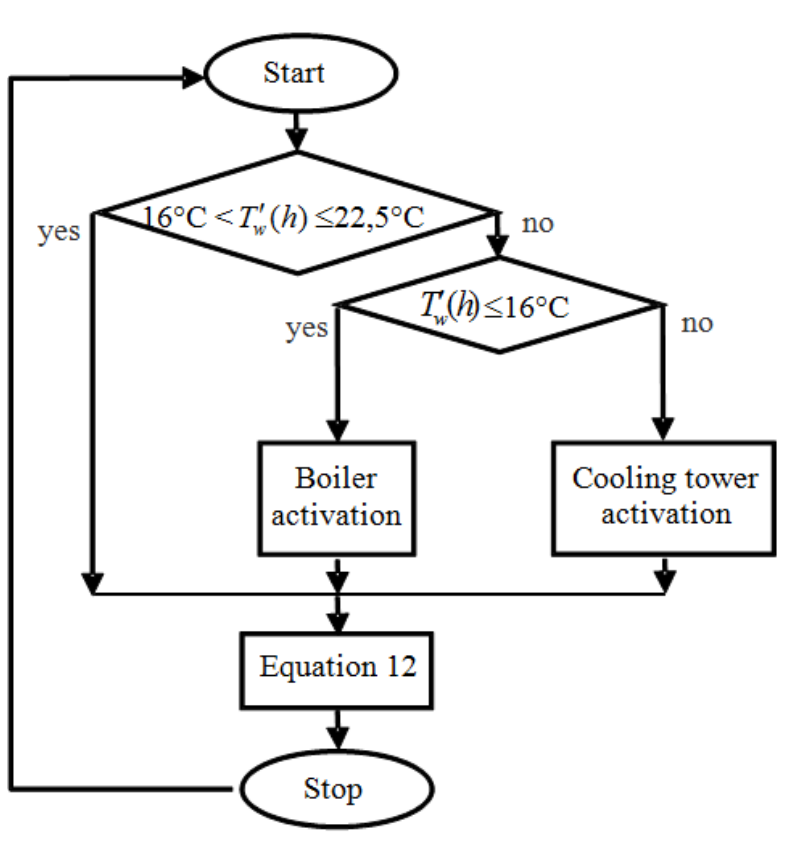

Fig. 4. WLHP temperature control flow chart

Table 2. Simulated WLHP system assumption

Water loop maximum flow rate, $\dot{m}_{w}=98 \mathrm{~kg} / \mathrm{s}$

Gas fired Boiler design capacity, $\dot{Q}_{B}=700 \mathrm{~kW}$

Gas fired Boiler efficiency, $\eta_{B}=0,90$

Natural gas heating value, $L H V=9,59 \mathrm{kWh} / \mathrm{Nm}^{3}$

Natural gas unitary cost, $c_{g}=0,50 € / \mathrm{Nm}^{3}$

Cooling tower design capacity, $\dot{Q}_{C T}=3000 \mathrm{~kW}$

Cooling tower fans rating, $\dot{L}_{\text {Fan }}=2 \times 30 \mathrm{~kW}$

Cooling tower pump rating, $\dot{L}_{P_{u m p}}=6,0 \mathrm{~kW}$

Cooling tower efficiency, $\eta_{C T}=0,40 \div 0,60$

Electricity unitary cost, $c_{e}=0,11 € / \mathrm{kWh}$

Design WLHP inlet water (cooling), $T_{\mathrm{w}}=44^{\circ} \mathrm{C}\left(\Delta T=6^{\circ} \mathrm{C}\right)$.

Minimum inlet water $T_{\mathrm{w}}=15^{\circ} \mathrm{C}$

Design WLHP inlet water (heating), $T_{\mathrm{w}}=15^{\circ} \mathrm{C}$

$\left(\Delta T<6^{\circ} \mathrm{C}\right)$. Maximum inlet water $T_{\mathrm{w}}=23^{\circ} \mathrm{C}$

Free cooling air flow rate: $100 \%$ design (large spaces), just ventilation (other spaces)

WLHP refrigerant fluid: R407c or R410a

In relation to the $W W$ chiller system the following algorithm is implemented in the code for each simulation hour, $h$ :

$Q_{E v}^{W W}(h)=\dot{Q}_{E v}^{W W}(h) \cdot \theta_{C}^{W W}(h)=\dot{Q}_{C o o l}(h) \cdot h$

where, $\dot{Q}_{E v}^{W W}(h)$ and $\theta_{C}^{W W}(h)$ are respectively the evaporator capacity and the running hourly ratio of the $W W$ chiller compressor. Note that, in the simulation code $\dot{Q}_{E v}^{W W}(h)$ and $\dot{L}_{C}^{W W}(h)$ depend hour by hour on the outdoor wet bulb temperature related to the TRY profile.
The $W W$ chiller system hourly primary energy consumption and operating cost result, respectively:

$$
\begin{aligned}
& E_{W W}(h)=\left(\dot{L}_{C}^{W W}(h)+\dot{L}_{C T}(h)\right) \cdot \theta_{C}^{W W}(h) / \eta_{P} \\
& C_{e, W W}(h)=\left(\dot{L}_{C}^{W W}(h)+\dot{L}_{C T}(h)\right) \cdot \theta_{C}^{W W}(h) \cdot c_{e}
\end{aligned}
$$

being, $\dot{L}_{C}^{W W}(h)$ and $\dot{L}_{C T}(h)$ the compressor and the cooling tower fans and pump ratings, respectively. In the occurring hour the water temperature exiting from the $W W$ chiller condenser and entering in the Traditional system Cooling Tower (TCT) is calculated by the following energy balance:

$$
\dot{Q}_{C o}^{W W}(h) \cdot \theta_{E v}^{W W}(h)=\left[\dot{m}_{w}^{W W}(h) \cdot c\left(T_{w}^{T C T}(h)-T_{w}^{\prime T C T}(h)\right)\right] h
$$

$T^{T C T}(h)$ is utilized by the code to get the cooling tower water temperature in the subsequent simulation time step.

The heat supplied by the Traditional system Boiler $(T B)$ to the building spaces in the simulation hour $h$, is calculated by the same algorithm reported in equation (1). The primary energy consumption and natural gas operating cost $\left(C_{g},{ }^{T B}\right)$ are assessed by equations similar to (2) and (3) respectively. Note that, here the boiler efficiency is assumed the same of the previous case despite of the lower heat distribution efficiency.

At the end of the simulation loop the THVAC system total operating cost is computed as:

$$
\left.C_{e, \text { year }}=\sum_{h}^{\text {year }}\left(C_{g, T B}(h)+C_{e, A W, W W}\right)(h)\right)
$$

In Table 3 all the assumptions considered in the simulation for the traditional systems are reported (the common assumptions between WLHP system and traditional one are shown in Table 2 only).

The carried out simulation starts on the first hour of January 1st and finishes on the last hour of December 31 st. The considered daily HVAC running period is from 7:00 am to $10: 00 \mathrm{pm}$ (15 $\mathrm{h}$ per day). In the performed calculations a steady state condition is assumed on each simulated hour $(h)$. For all the considered simulations the indoor air design temperature in cooling and heating modes are respectively 26 and $20^{\circ} \mathrm{C}$. The water loop flow rate changes according to the hourly global building loads. During winter, free cooling is activated if necessary. The capital cost of innovative and traditional systems and the operating cost due to the space air diffusion of WLHP and traditional systems are assumed to be almost the same and for such a reason are not included in this analysis (Lian et al., 2005). 
Table 3. Simulated THVAC system assumption

Water flow rate, $\dot{m}_{w}=98 \mathrm{~kg} / \mathrm{s}$

Design heating water temperatures $=45 \div 40^{\circ} \mathrm{C}$

Design cooling water temperatures $=7 \div 12^{\circ} \mathrm{C}$

Chiller design capacity, $\dot{Q}_{A W}=2200 \mathrm{~kW}$

Cooling $T H V A C$ systems supply water, $T_{w}=7^{\circ} \mathrm{C}$

Design cooling tower water $\Delta T=6^{\circ} \mathrm{C}$

Cooling tower design capacity, $\dot{Q}_{C T}=3200 \mathrm{~kW}$

Cooling tower fans rating, $\dot{L}_{F a n}=2 \times 36 \mathrm{~kW}$

Cooling tower pump rating, $\dot{L}_{\text {Pump }}=2 \times 5,5 \mathrm{~kW}$

Design $A W$ chiller inlet air, $T=44^{\circ} \mathrm{C}\left(\Delta T=6^{\circ} \mathrm{C}\right)$. Minimum inlet air $T=20^{\circ} \mathrm{C}$

Design $W W$ chiller inlet water, $T_{\mathrm{w}}=50^{\circ} \mathrm{C}\left(\Delta T=6^{\circ} \mathrm{C}\right)$. Minimum inlet water $T_{\mathrm{w}}=25^{\circ} \mathrm{C}$

\section{Results and Discussion}

The investigation is referred to a building pavilion where a self-sufficient purposely designed WLHP system is modelled. Although it represents only the $20 \%$ of the total surface area of the whole "Vulcano Buono" mall building, a significant heating/cooling load simultaneity is detected.

Different combinations of boiler and cooling tower activation temperatures (within those allowed in Table 1) and relative running control logics are processed in order to find out the optimal one from the thermodynamic and economic points of view. Note that, the best water loop temperature depends on: The weather of the considered geographic site; the indoor spaces load; the number of WLHPs simultaneously in cooling and heating mode operation (Wang, 2001). The present analysis is aimed at finding out the most suitable utilization of boiler and cooling tower in order to obtain the highest system energy efficiency. Note that, the developed code takes into account the machines heating and cooling COP variations as a function of the water loop temperature. For the present analysis the outdoor climatic conditions are simulated by the TRY hourly data relative to the Italian climatic area of the middle-south Tyrrhenian Sea coast (where the considered building is located).

The spaces cooling and heating loads calculation and the WLHPs running mode selection are hourly carried out by the generated computer code. In Fig. 5 the global heat load profile on the water loop $\left(\dot{Q}_{W L, T O T}\right)$ is reported for three sample days of January (when a loads simultaneity is detected) and qualitatively for the whole simulated season (high side of the figure). In the same figure, the trends of global heating and cooling loads on the water loop are also shown.

In Table 4, for the considered case study, the control temperatures and the hypothesized actions for boiler and cooling tower minimizing the energy and economic WLHP system costs are reported. The considered reference governor is based on engineering considerations and heuristic rules as it is explained in the following. Note that, in the developed model the $T_{w}^{\prime}$ sensor is located after the system actuator.

For both the boiler and the cooling tower different running logics are considered.

If only heating is required from the WLHPs, the loop water temperature can be decreased until $10^{\circ} \mathrm{C}$ (Table 1) and since the boiler operating cost to maintain higher water temperatures is resulted not counterbalanced by the savings due to the higher WLHPs COP, this limit should be always approached. For the present study this case would be reached for daily outdoor temperature at all times lower than $3.5^{\circ} \mathrm{C}$. Note that, for the considered case study such circumstance never occurs. In Table $4 T_{w}^{*}(h)$ is the desired boiler exiting temperature.

During the period when both heating and cooling are simultaneously required by the WLHPs the loop water temperature has to be maintained by the boiler up to $15^{\circ} \mathrm{C}$ and lowered by the cooling tower down to $23^{\circ} \mathrm{C}$ (Table 1). In the present simulation this season occurs from the beginning of the year to the $104^{\text {th }}$ day and from the $304^{\text {th }}$ day to the end of the year. This case is reached for daily outdoor temperature at all times lower than $10.5^{\circ} \mathrm{C}$.

For the cooling tower the steeper is the water loop temperature increasing trend, the stronger and timely is the considered device reaction. Here, different operation steps are modeled: When the outdoor air temperature is lower than the water loop one a free cooling of water is activated using the cooling tower as a dry heat exchanger with an efficiency of $25 \%$. In case that such process is not sufficient to decrease the water temperature (i.e., for still high exiting temperature $T_{w}^{\prime}(h)$, Table 4$)$ the cooling tower water pumps are activated with a cooling tower efficiency of $25 \%$. For harder working conditions one fan is switched on and the cooling tower efficiency increases to $40 \%$. For this running period the suitable system standby temperature interval ranges from 16 to $22.5^{\circ} \mathrm{C}$. Note that, other set point temperatures and control strategies were simulated obtaining higher system operating costs or surpassing the design water temperature limits (Table 1 ).

In Fig. 6 the temperature profile of the water loop $\left(T_{w}^{\prime}\right)$ is reported for the same three days of previous graph and for the whole simulated season. Here, the trends of the TRY outdoor air dry bulb and wet bulb temperatures are also shown. Note that the water loop temperatures are maintained by the boiler and the cooling tower within the seasonal limits of 15 and $23^{\circ} \mathrm{C}$.

In Figure 6 the temperature profile of the water loop $\left(T_{w}^{\prime}\right)$ is reported for the same three days of previous graph and for the whole simulated season. Here, the trends of the TRY outdoor air dry bulb and wet bulb temperatures are also shown. Note that the water loop temperatures are maintained by the boiler and the cooling tower within the seasonal limits of 15 and $23^{\circ} \mathrm{C}$. 


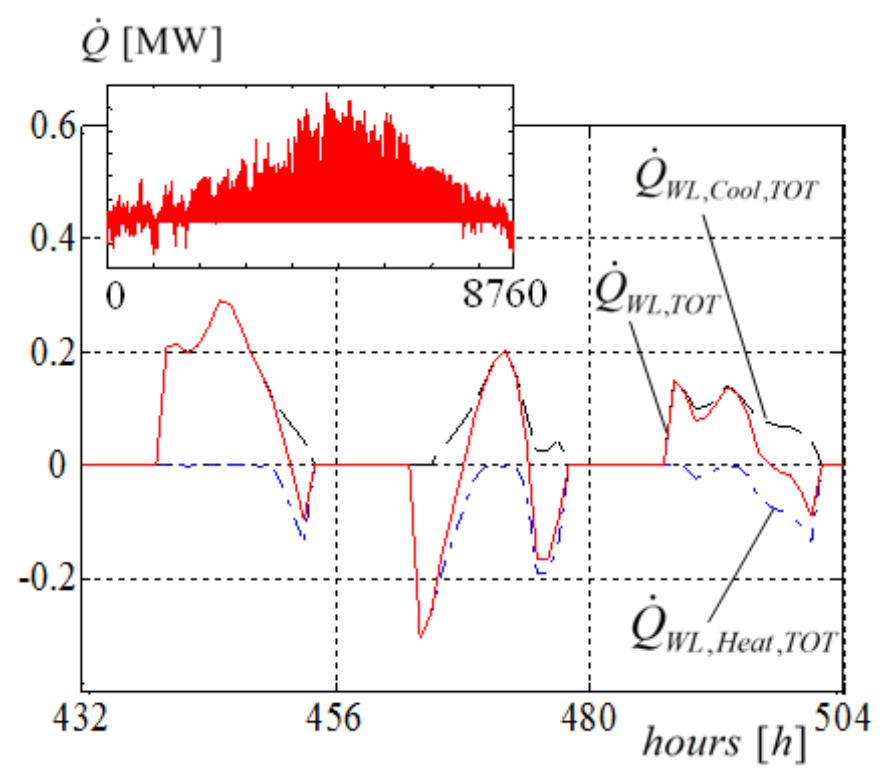

Fig. 5. Hourly heat load profiles

\section{$T\left[{ }^{\circ} \mathrm{C}\right]$}

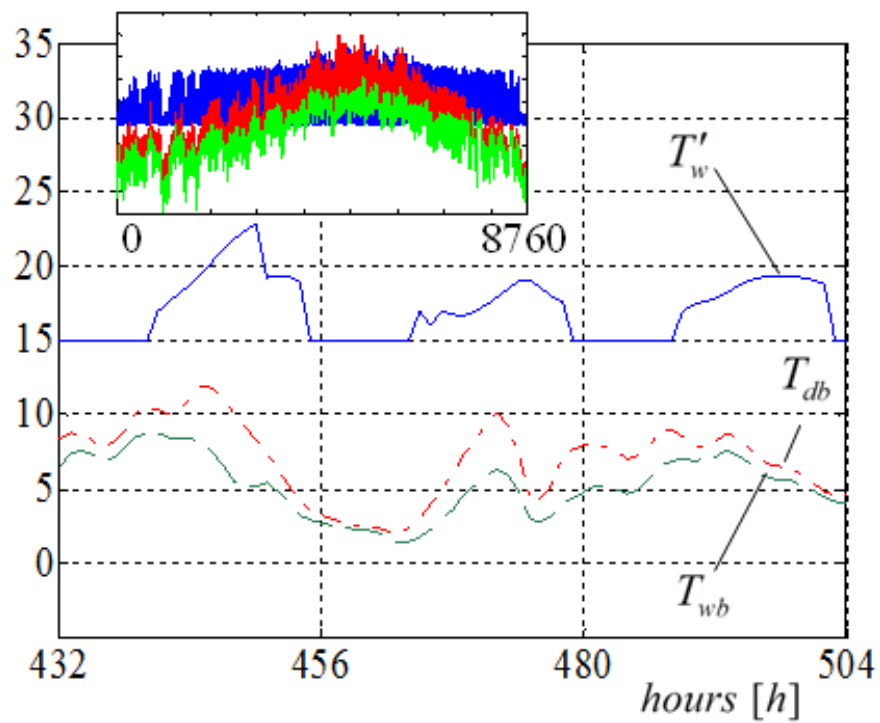

Fig. 6. Hourly temperature profiles

If only cooling is required from the WLHPs (for the simulated case study between $104^{\text {th }}$ and $304^{\text {th }}$ day of the year) the previous water temperature limit of $23^{\circ} \mathrm{C}$ can be surpassed. On the other hand the water loop temperature has to be as low as possible in order to maximize the WLHPs cooling COP without exceeding the operating costs of the cooling tower. Note that, in this case for heavy working conditions a second fan in the cooling tower can be activated increasing its efficiency to $60 \%$. The summer best performance investigation is referred to simulated activation temperatures of the cooling tower ranging from 15 to $44^{\circ} \mathrm{C}$ (Table 1$)$.

In Figure 7 the profiles of the system primary energy (E) consumptions as a function of such activation temperatures $\left(T_{w, C T, \text { summer }}^{\prime}\right)$ are reported. Note that, the total energy consumption trend shows a minimum between 23 and $26^{\circ} \mathrm{C}$ (Table 4). 


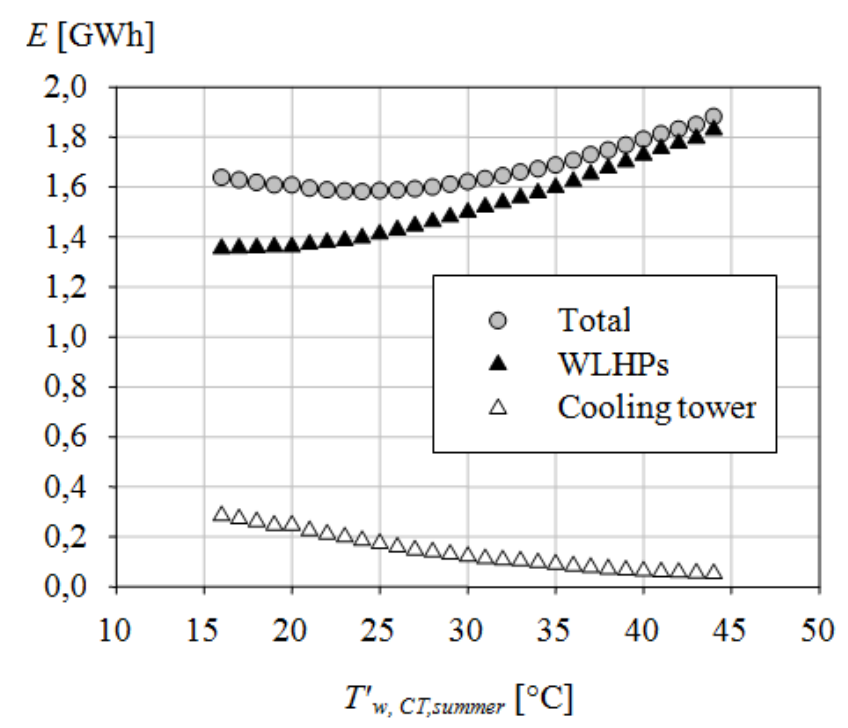

Fig. 7. Summer primary energy consumption

Table 4. Boiler and cooling tower control strategy

\begin{tabular}{|c|c|c|c|}
\hline Device/season & & Control & Action \\
\hline \multirow[t]{4}{*}{ Boiler } & Heating only & $T_{w}^{\prime}(h) \leq 11^{\circ} \mathrm{C}$ & $T_{w}^{*}(h)=12^{\circ} \mathrm{C}$ \\
\hline & & $T_{w}^{\prime}(h)>10.5^{\circ} \mathrm{C}$ & standby \\
\hline & Heating and cooling & $T_{w}^{\prime}(h) \leq 16^{\circ} \mathrm{C}$ & $T_{w}^{*}(h)=17^{\circ} \mathrm{C}$ \\
\hline & & $16^{\circ} \mathrm{C}<T_{w}^{\prime}(h) \leq 22.5^{\circ} \mathrm{C}$ & standby \\
\hline \multirow[t]{11}{*}{ Cooling tower } & & $T_{w}^{\prime}(h)>22.5^{\circ} \mathrm{C}$ & $\eta_{d b, C T}=0.25$ \\
\hline & & $T_{w}^{\prime}(h)>T_{d b}(h)$ & $\dot{L}_{C T}=0 \mathrm{~kW}$ \\
\hline & & $T_{w}^{\prime}(h)>22.5^{\circ} \mathrm{C}$ & $\eta_{w b, C T}=0.25$ \\
\hline & & $0^{\circ} \mathrm{C} \leq T_{w}^{\prime}(h)-T_{w}^{\prime}(h-1)<3^{\circ} \mathrm{C}$ & $\dot{L}_{C T}=6 \mathrm{~kW}$ \\
\hline & & $T_{w}^{\prime}(h)>22.5^{\circ} \mathrm{C}$ & $\eta_{w b, C T}=0.4$ \\
\hline & & $T_{w}^{\prime}(h)-T_{w}^{\prime}(h-1)>3^{\circ} \mathrm{C}$ & $\dot{L}_{C T}=36 \mathrm{~kW}$ \\
\hline & Cooling only & $T_{w}^{\prime}(h) \leq 24^{\circ} \mathrm{C}$ & standby \\
\hline & & $T_{w}^{\prime}(h)>25^{\circ} \mathrm{C}$ & $\eta_{w b, C T}=0.6$ \\
\hline & & $T_{w}^{\prime}(h)-T_{w}^{\prime}(h-1) \geq 2^{\circ} \mathrm{C}$ & $\dot{L}_{C T}=66 \mathrm{~kW}$ \\
\hline & & $T_{w}^{\prime}(h)>26^{\circ} \mathrm{C}$ & $\eta_{w b, C T}=0.4$ \\
\hline & & $0^{\circ} \mathrm{C} \leq T_{w}^{\prime}(h)-T_{w}^{\prime}(h-1)<2^{\circ} \mathrm{C}$ & $\dot{L}_{C T}=36 \mathrm{~kW}$ \\
\hline
\end{tabular}

For the considered case study the minimum yearly primary energy consumption and operating cost are respectively $1.98 \mathrm{GWh} / \mathrm{y}$ and $93.2 \mathrm{k} € / \mathrm{y} .86 .7 \%$ of this cost is due to the WLHPs, $5.38 \%$ to the boiler and $7.97 \%$ to the cooling tower. The operating cost of the WLHPs is thus $80.8 \mathrm{k} € / \mathrm{y}$ of which $17.3 \%$ for heating and cooling in winter and $82.7 \%$ for cooling during summer.

Passing to the performance comparison of the WLHP system vs. the traditional one, the following results are obtained. Referring to the best WLHP system performance the primary energy saving vs. the Air to
Water $(A W)$ chiller and boiler is $8.02 \%$. From the environmental point of view the $\mathrm{CO}_{2}$ surplus vs. the WLHP system results $31 \mathrm{t} / \mathrm{y}(-7.3 \%)$. The energy saving vs. the Water to Water $(W W)$ chiller and boiler appears higher, being $20.0 \%$. The better performance of the $A W$ heat pump vs. the $W W$ one is due to the absence of the cooling tower operating costs that for the considered climatic area are not counterbalanced by a sufficient COP increase of the $W W$ chiller. From the environmental point of view the $\mathrm{CO}_{2}$ surplus vs. the WLHP system results in this case $78 \mathrm{t} / \mathrm{y}(-17 \%)$. 


\section{Conclusion}

Target of this paper is the analysis of the energy, economic and environmental performances of buildingHVAC systems. In particular, for the WLHP systems, a custom designed simulation model and computer code are presented. The building-WLHP system analysis starts from the local hourly climatic data for the assessment of the spaces heating and cooling loads and for detecting their simultaneity.

Although the simplified approach does not allow accurate system feasibility or operating analyses, interesting guidelines can be find out by the developed tool. In particular, details about the optimal setting of the system operating conditions aimed at reach the lowest energy and economic costs are provided by taking into account the system constraints and avoiding the traditional empirical attempts. Special attention is paid for comparing the WLHP system performance to the traditional systems ones.

A case study related to a large commercial building pavilion is finally reported as an application example. Referring to the considered climatic area (Naples, South Italy) and spaces loads, the following simulation results are obtained:

- For the considered case study a period with only heating is not detected, while significant number of occurrences for only cooling and cooling and heating periods are obtained

- The minimum global energy consumption and operating cost of the WLHP system are obtained for

The period with heating and cooling simultaneity, in correspondence of a large standby boiler-cooling tower temperature interval (low boiler and high cooling tower exiting temperatures compatible with the system constraints) resulting the WLHPs COP increase not sufficient to counterbalance the higher operating costs necessary to a standby interval reduction. Here, a remarkable dependence on the system performance is paid to the boiler operating temperatures (compatibly with the system constraints, the lower is this temperature and the lower is the global operating cost). Regarding the cooling tower, the performance dependence on its control temperatures appears rather small, especially at the low boiler exiting temperatures.

The only cooling mode period, in correspondence of a cooling tower activation temperature around $25^{\circ} \mathrm{C}$. At this temperature the lowest sum of the WLHPs and cooling tower operating costs is achieved.

- Moderate or significant energy saving are detected respectively Vs. traditional systems (consisting of air to water and water to water chillers and gas fired boiler)
Future perspectives will deal with WLHP system applications to cold stores, supermarkets, solar heating devices and other systems where heat can be recovered by the water loop.

\section{Funding Information}

The authors have no support or funding to report.

\section{Author's Contributions}

All authors contributed equally to this work, they also revised and approved the manuscript.

\section{Ethics}

This article is original and contains unpublished material. The corresponding author confirms that all of the other authors have read and approved the manuscript and no ethical issues involved.

\section{References}

ASHRAE, 2005. ASHRAE Handbook. American Society of Heating, Refrigerating and AirConditioning Engineers.

Buonomano, A., F. Calise and A. Palombo, 2012. Buildings dynamic simulation: Water loop heat pump systems analysis for European climates. Applied Energy, 91: 222-234. DOI: 10.1016/j.apenergy.2011.09.031

CEC, 1985. Test Reference Years Try. Weather Data Sets for Computer Simulations of Solar Energy Systems and Energy Consumption in Buildings. 1st Edn., EC, Luxembourg, pp: 48.

Chen, C., F.l. Sun, L. Feng and M. Liu, 2005. Underground water-source loop heat-pump airconditioning system applied in a residential building in Beijing. Applied Energy, 82: 331-344.

DOI: $10.1016 / \mathrm{j}$.apenergy.2004.12.002

CLIVET, 2007. WLHP technical data. Italy.

Ferruzzi, G., G. Cervone, L. Delle Monache, G. Graditi, F. Jacobone, 2016. Optimal bidding in a Day-Ahead energy market for Micro Grid under uncertainty in renewable energy production. Energy, 106: 194-202. DOI: $10.1016 /$ j.energy.2016.02.166

Gottfried, D.A., E.A. Schoichet and M. Hart, 1997. Green building environmental control: A case study. HPAC, 2: 71-78.

Lian, Z., S.R. Park and H. Qi, 2005. Analysis on energy consumption of water-loop heat pump system in China. Applied Thermal Eng., 25: 73-85.

DOI: $10.1016 /$ j.applthermaleng.2004.06.002

Lian, Z., S.R. Park, W. Huang, Y.J. Baik and Y. Yao, 2005. Conception of combination of gas-enginedriven heat pump and water-loop heat pump system. Int. J. Refrigerat., 28: 810-819.

DOI: $10.1016 / j$.jijrefrig.2005.02.004 
Pérez-Lombard, L., J. Ortiz, J.F. Coronel and I.R. Maestre, 2011. A review of HVAC systems requirements in building energy regulations. Energy Build., 43: 255-268.

DOI: $10.1016 /$ j.enbuild.2010.10.025

Wang, S.K., 2001. Handbook of Air Conditioning and Refrigeration. 2nd Edn., McGraw-Hill, New York, ISBN-10: 0071189815, pp: 1232.
Xinguo, L., 1998. Thermal performance and energy saving effect of water-loop heat pump systems with geothermal. Energy Convers. Manage., 39: 295-301. DOI: 10.1016/S0196-8904(96)00189-6

Yuan, S. and M. Grabon, 2011. Optimizing energy consumption of a water-loop variable-speed heat pump system. Applied Thermal Eng., 31: 894-901. DOI: $10.1016 /$ j.applthermaleng.2010.11.012 